\title{
Bone and mineral disorders in pre-dialysis CKD
}

\author{
Csaba P. Kovesdy $\cdot$ Kamyar Kalantar-Zadeh
}

Published online: 23 April 2008

(C) Springer Science+Business Media B.V. 2008

\section{Erratum to: Int Urol Nephrol DOI \\ 10.1007/s11255-008-9346-7}

In Table 2 of the original publication, the statement that Lanthanum carbonate is "Not allowed in liver disease" is not accurate.

The online version of the original article can be found under doi:10.1007/s11255-008-9346-7.

C. P. Kovesdy $(\square)$

Division of Nephrology, Salem VA Medical Center, 1970 Roanoke Boulevard, Salem, VA 24153, USA

e-mail: csaba.kovesdy@va.gov

C. P. Kovesdy

University of Virginia, Charlottesville, VA, USA

K. Kalantar-Zadeh

Harold Simmons Center for Kidney Disease Research and Epidemiology, Torrance, CA 90502, USA

K. Kalantar-Zadeh

Division of Nephrology and Hypertension, Los Angeles

Biomedical Research Institute at Harbor-UCLA Medical

Center, Torrance, CA 90502, USA

K. Kalantar-Zadeh

David Geffen School of Medicine at UCLA, Torrance,

CA 90502, USA 